\title{
Effect of occupational air pollutants on various histological types of lung cancer: a population based case-control study
}

\author{
H Becher, W Jedrychowski, J Wahrendorf, Z Basa-Cierpialek, E Flak, K Gomola
}

\begin{abstract}
A population based case-control study was performed in Cracow, Poland, to determine the effect of occupational air pollutants on various histological types of lung cancer. Male cases and controls were identified from the Cracow Death Register. Information was obtained by mailed questionnaire from next of kin on smoking, occupational branch, occupational exposures, and other pertinent variables. Response rates were $73.5 \%$ in cases and $72.0 \%$ in controls. For cases that underwent a bronchial biopsy or surgical excision the histological diagnosis of the tumour was obtained from clinical records. The case group contained 343 subjects with squamous cell carcinomas, 151 with small cell carcinomas, and 106 with adenocarcinomas. Twenty seven cases showed other histological types (large cell carcinoma and not classifiable). Analysis was performed separately by histological type for occupational exposure variables adjusted for smoking. Long term exposure to mineral dust and metal dust ( 20 years or more) was found to be a significant risk factor for small cell and squamous cell carcinoma. The effect was more pronounced if the analysis was restricted to those aged less than 70 years. The highest relative risk (RR) due to occupational exposures was found for squamous cell carcinoma and exposure to mineral dust for more than 20 years $(R R=2 \cdot 45,95 \%$ CI $1 \cdot 43-4 \cdot 19)$. The estimated effect of mineral dust on small cell carcinoma and adenocarcinoma was smaller $(\mathbf{R R}=2 \cdot 29,95 \%$ CI $1 \cdot 16-4 \cdot 53$ and $R R=2 \cdot 04,95 \%$ CI 0.89-4.64 respectively). The effect of metal
\end{abstract}

German Cancer Research Centre, Institute of Epidemiology and Biometry, Im Neuenheimer Feld 280, 6900 Heidelberg, Germany

$\mathrm{H}$ Becher, J Wahrendorf

Department of Epidemiology, Institute of Social

Medicine, Medical School, Cracow, Poland

W Jedrychowski, Z Basa-Cierpialek, E Flak, K Gomola dust and fumes seemed about the same for squamous and small cell carcinoma. No specific agent could be identified as particularly important for a specific histological type; it rather seemed that the effects of the substances considered were similar for lung cancers in general.

(British Journal of Industrial Medicine 1993;50:136-142)

Several chemicals and industrial hazards are known to increase the risk of lung cancer and are of considerable hazard for many industrial subpopulations. ${ }^{1-7}$ Smoking, however, is the dominant aetiological risk factor for lung cancer. Assuming a multifactorial cause of cancer, it may be expected that cigarette smoke, being a combination of specific carcinogenic substances and of irritant chemicals sufficient in themselves to produce cancer, can potentiate or be potentiated by other environmental agents. In fact, smoking and occupational exposures to compounds that are carcinogenic often seem to interact in a synergistic way. This has been found for asbestos, arsenic, and radon daughters. ${ }^{8-11}$ Some reports also suggest a multiplicative type of interaction between smoking and exposure to community air pollution. ${ }^{12} 13$

Most epidemiological studies of the association between environmental factors and lung cancer treat respiratory cancers as a single entity. It is suggested, however, that individual histological types of respiratory cancers could be considered as distinct disease entities that may have different environmental determinants. ${ }^{14-17}$ In recent years, interest in the epidemiology of the specific histological categories of lung cancer have increased because recognition of such distinctions may enhance our knowledge of the pathogenesis of respiratory cancers. In a recent study by Hoar et al ${ }^{18}$ several occupational groups were considered; however, no specific agents were identified that may have different effects on different histological types of lung cancer.

To investigate occupational contributions to lung cancer, a population based case-control study was undertaken, and distributions of lung cancer cell types in exposed and non-exposed subjects from the 
Table 1 Age distribution for controls and cases by histological type

\begin{tabular}{|c|c|c|c|c|c|}
\hline \multirow[b]{3}{*}{ Age group } & \multirow[b]{2}{*}{ Controls } & \multicolumn{4}{|l|}{ Cases } \\
\hline & & $\begin{array}{l}\text { Squamous cell } \\
\text { carcinoma }\end{array}$ & $\begin{array}{l}\text { Small cell } \\
\text { carcinoma }\end{array}$ & Adenocarcinoma & Others* \\
\hline & No $(\%)$ & No $(\%)$ & No (\%) & No $(\%)$ & No $(\%)$ \\
\hline $\begin{array}{l}\leqslant 49 \\
50-59 \\
60-69 \\
70-79 \\
\geqslant 80\end{array}$ & $\begin{array}{lr}129 & (9 \cdot 6) \\
262 & (19 \cdot 5) \\
341 & (25 \cdot 4) \\
418 & (31 \cdot 1) \\
193 & (14 \cdot 4)\end{array}$ & $\begin{array}{rr}29 & (8 \cdot 5) \\
117 & (34 \cdot 1) \\
125 & (36 \cdot 4) \\
65 & (19 \cdot 0) \\
7 & (2 \cdot 0)\end{array}$ & $\begin{array}{rr}14 & (9 \cdot 3) \\
52 & (34 \cdot 4) \\
54 & (35 \cdot 8) \\
25 & (16 \cdot 6) \\
6 & (4 \cdot 0)\end{array}$ & $\begin{array}{rr}12 & (11 \cdot 3) \\
34 & (32 \cdot 1) \\
35 & (33 \cdot 0) \\
22 & (20 \cdot 8) \\
3 & (2 \cdot 8)\end{array}$ & $\begin{array}{lc}3 & (11 \cdot 1) \\
8 & (29 \cdot 6) \\
8 & (29 \cdot 6) \\
6 & (22 \cdot 2) \\
2 & (7 \cdot 4)\end{array}$ \\
\hline Total & $1343(100 \cdot 0)$ & $343(100 \cdot 0)$ & $151(100 \cdot 0)$ & $106(100 \cdot 0)$ & $27(100 \cdot 0)$ \\
\hline Mean age & $66 \cdot 3$ & $61 \cdot 7$ & $60 \cdot 9$ & 61.9 & 61.9 \\
\hline
\end{tabular}

^Large cell carcinoma and not classifiable.

general population have been compared. A further objective of the analysis was to estimate the burden of different histological types of lung cancer attributable to different occupational air pollutants with various criteria of exposure while controlling for smoking and other confounders. The study therefore adds more detail to the investigation of Simonato et al ${ }^{19}$ who estimated the proportion of lung cancer in general that was attributable to occupational exposure.

\section{Materials and methods}

A total of 1948 male residents of Cracow whose deaths were attributed to lung cancer on the death certificate and whose deaths occurred between 1 January 1980 and 31 December 1987 were identified. Information from 1432 cases was received giving a response rate of $73.5 \%$. The control subjects were selected from the Cracow Death Register as the first entry of the same sex, same age ( \pm five years) and same date of death ( \pm one month) after each case with a death other than respiratory diseases or smoking related cancers. Through this procedure 1865 controls were selected. For 83 cases no control was identified that met all matching criteria. Information from 1323 controls was received giving a response rate of $72.0 \%$. If a selected control to a particular case was a non-respondent, no effort was made to select another control. Similarly, a control was included in the analysis group even if the corresponding case was a non-respondent. This procedure ensured a similar age distribution in cases and controls (frequency matched design) by using the age of each case as an auxiliary variable.

Data on histological type of lung cancer diagnosed by bronchial biopsy or surgical excision were extracted from available clinical records of the cases. Data from cytological examination have not been taken into consideration. In total, out of 1432 subjects with diagnosis of lung cancer and whose next of kin were interviewed the results of histological examination for 627 male subjects $(43.8 \%)$ were found in the clinical histories. The largest histological group was squamous cell carcinoma ( 343 cases); then small cell carcinoma (151 cases) and adenocarcinoma (106 cases). There were 27 cases of large cell carcinoma or unspecified carcinomas (see table 1).

A structured postal questionnaire was sent to next of kin of the cases and controls enquiring about sociodemographic characteristics, occupational history, smoking habits, and other variables of interest. To avoid possible bias induced by different attitudes among cases and controls for recalling specific exposures, the introductory letter addressed to the next of kin of cases and controls was identical and explained that the study was undertaken to evaluate mortality in the Cracow area without mentioning any specific hazards. The occupational history covered branch of industry (for example, iron, steel, and metal industry, chemical industry, brick manufacturing, cement industry) of the longest held job, duration of work, job category (manual $v$ nonmanual), exposure to suspected occupational hazards (for example, mineral dust of various industrial origins, metal dusts and metal fumes, chemicals of various origins) and its duration. To assess exposure to occupational dusts or fumes the criteria were based on the specific questions irrespective of the branch of industry. In the analysis of occupation, jobs other than the ones held longest were not considered. Changing jobs is less common in Poland than in western countries. The three largest exposure groups (mineral dusts, cement, and metal dusts or metal fumes) were formed, and each was divided subsequently into two exposure levels (less than 20 years of exposure or unknown duration, and 20 years or more). In this approach workers exposed to other occupational factors were treated as "other exposure category" and the remaining group served as the non-exposed baseline category.

The data on smoking habits included the year the 
Table 2 Branch of industry in controls and cases (longest held job)

\begin{tabular}{|c|c|c|c|c|}
\hline \multirow[b]{3}{*}{ Occupation } & \multirow[b]{2}{*}{ Controls } & \multicolumn{3}{|l|}{ Cases } \\
\hline & & $\begin{array}{l}\text { Squamous } \\
\text { cell carcinoma }\end{array}$ & $\begin{array}{l}\text { Small } \\
\text { cell carcinoma }\end{array}$ & Adenocarcinoma \\
\hline & No $(\%)$ & No $(\%)$ & No $(\%)$ & No $(\%)$ \\
\hline $\begin{array}{l}\text { Foundry and metal industry } \\
\text { Building and construction } \\
\text { Transport } \\
\text { Chemical industry } \\
\text { Coal mine } \\
\text { Agriculture } \\
\text { Other } \\
\text { Missing }\end{array}$ & $\begin{array}{rr}184 & (13 \cdot 70) \\
101 & (7 \cdot 52) \\
93 & (6 \cdot 92) \\
32 & (2 \cdot 38) \\
6 & (0 \cdot 45) \\
38 & (2 \cdot 83) \\
499 & (37 \cdot 16) \\
390 & (29 \cdot 04)\end{array}$ & $\begin{array}{rr}59 & (17.20) \\
32 & (9.33) \\
38 & (11.08) \\
13 & (3.79) \\
0 & (0.00) \\
5 & (1.46) \\
108 & (31.49) \\
88 & (25.66)\end{array}$ & $\begin{array}{rr}30 & (19 \cdot 87) \\
12 & (7 \cdot 95) \\
11 & (7 \cdot 28) \\
5 & (3 \cdot 31) \\
1 & (0 \cdot 66) \\
4 & (2 \cdot 65) \\
56 & (37 \cdot 09) \\
32 & (21 \cdot 19)\end{array}$ & $\begin{array}{rr}22 & (20.75) \\
7 & (6.60) \\
8 & (7.55) \\
2 & (1.89) \\
0 & (0.00) \\
1 & (0.94) \\
28 & (26.42) \\
38 & (35.85)\end{array}$ \\
\hline Total & 1343 & 343 & 151 & 106 \\
\hline
\end{tabular}

subjects started smoking, the average number of cigarettes smoked daily, and the duration of smoking. The lifetime smoking was estimated and expressed in pack-years. Detailed results on smoking are given elsewhere. ${ }^{20}$

For estimation of relative risk (RR) logistic regression models ${ }^{21}$ were fitted to the data with the SAS (Statistical Analysis System) software package for unconditional maximum likelihood estimation of the regression parameters. In all analyses there was an adjustment for age (five age groups) and smoking (never smokers, $1-19,20-29$, or $\geqslant 30$ cigarettes daily, time since stopping smoking (five to nine years, 10 years or more). The $95 \%$ confidence intervals are given and are based on the normal approximation of the estimated regression coefficients. In the multivariate analyses we considered the occupational exposure variables simultaneously and separately to show the effect of multicollinearity among these variables. Some analyses were also done separately for the subgroup of people under 70 years of age.

\section{Results}

The mean age of controls was 66 , for small cell carcinoma 61, and for other histological types 62 . Most of the cases of lung cancer with a histological diagnosis were in the age group 50-69 (433 cases); 58 cases were younger, and 136 were older. For all age groups squamous cell carcinoma was found in $54 \cdot 7 \%$, small cell carcinoma in $24 \cdot 1 \%$, and adenocarcinoma in $16.9 \%$ of cases. Large cell carcinoma and lung cancer cell type not classifiable were found in $4.3 \%$ of cases. In each age group there were roughly equal proportions of each histological type (table 1).

Among controls $78.5 \%$ were smokers, $98.2 \%$ were smokers in the squamous and the small cell carcinoma group, and $93.4 \%$ in the adenocarcinoma group.

Table 3 Duration of industrial exposure to various substances in controls and cases

\begin{tabular}{|c|c|c|c|c|c|}
\hline \multirow[b]{3}{*}{ Exposure } & \multirow[b]{3}{*}{ Duration } & \multirow[b]{2}{*}{ Controls } & \multicolumn{3}{|l|}{ Cases } \\
\hline & & & $\begin{array}{l}\text { Squamous } \\
\text { cell carcinoma }\end{array}$ & $\begin{array}{l}\text { Small } \\
\text { cell carcinoma }\end{array}$ & Adenocarcinom \\
\hline & & No $(\%)$ & No $(\%)$ & No $(\%)$ & No (\%! \\
\hline $\begin{array}{l}\text { Mineral dust of various } \\
\text { origins }\end{array}$ & $\begin{array}{l}\text { No exposure } \\
1-19 y \\
20-29 y \\
\geqslant 30 y \\
\text { Duration of exposure missing }\end{array}$ & $\begin{array}{rr}1154 & (85.93) \\
67 & (4.99) \\
52 & (3.87) \\
49 & (3.65) \\
21 & (1.56)\end{array}$ & $\begin{array}{rr}254 & (74 \cdot 05) \\
19 & (5 \cdot 54) \\
24 & (7 \cdot 00) \\
37 & (10 \cdot 79) \\
9 & (2 \cdot 62)\end{array}$ & $\begin{array}{rr}118 & (78 \cdot 15) \\
9 & (5 \cdot 96) \\
13 & (8 \cdot 61) \\
11 & (7 \cdot 28) \\
0 & (0 \cdot 00)\end{array}$ & $\begin{array}{rr}83 & (78 \cdot 30) \\
4 & (3 \cdot 77) \\
10 & (9 \cdot 43) \\
7 & (6 \cdot 60) \\
2 & (1 \cdot 89)\end{array}$ \\
\hline Cement dust & $\begin{array}{l}\text { No exposure } \\
1-19 y \\
20-29 y \\
\geqslant 30 y \\
\text { Duration of exposure missing }\end{array}$ & $\begin{array}{rr}1177 & (87.64) \\
49 & (3.65) \\
48 & (3.57) \\
46 & (3.43) \\
23 & (1.71)\end{array}$ & $\begin{array}{rr}277 & (80 \cdot 76) \\
17 & (4 \cdot 96) \\
19 & (5 \cdot 54) \\
27 & (7 \cdot 87) \\
3 & (0.87)\end{array}$ & $\begin{array}{rr}123 & (81.46) \\
6 & (3.97) \\
10 & (6.62) \\
11 & (7 \cdot 28) \\
1 & (0.66)\end{array}$ & $\begin{array}{rr}86 & (81 \cdot 13) \\
4 & (3 \cdot 77) \\
7 & (6 \cdot 60) \\
7 & (6 \cdot 60) \\
2 & (1 \cdot 89)\end{array}$ \\
\hline $\begin{array}{l}\text { Metal dusts or metal } \\
\text { fumes }\end{array}$ & $\begin{array}{l}\text { No exposure } \\
1-19 y \\
20-29 y \\
\geqslant 30 y \\
\text { Duration of exposure missing }\end{array}$ & $\begin{array}{rr}1138 & (84 \cdot 74) \\
49 & (3 \cdot 65) \\
66 & (4 \cdot 91) \\
58 & (4 \cdot 32) \\
32 & (2 \cdot 38)\end{array}$ & $\begin{array}{rr}261 & (76 \cdot 09) \\
12 & (3.50) \\
29 & (8 \cdot 45) \\
33 & (9 \cdot 62) \\
8 & (2 \cdot 33)\end{array}$ & $\begin{array}{rr}112 & (74 \cdot 17) \\
7 & (4 \cdot 64) \\
16 & (10 \cdot 60) \\
14 & (9 \cdot 27) \\
2 & (1.32)\end{array}$ & $\begin{array}{rr}85 & (80.19) \\
4 & (3.77) \\
8 & (7.55) \\
9 & (8.49) \\
0 & (0.00)\end{array}$ \\
\hline & Total & 1343 & 343 & 151 & 106 \\
\hline
\end{tabular}


In the control series there was a lower percentage of manual workers $(44.9 \%)$ than in the case series $(52.8 \%)$; conversely, in the case series there were more clerical workers than in the control series $(27.0 \% v 21.2 \%)$. In $28.1 \%$ of subjects from the control group and in $25.8 \%$ from the case series data on occupational category were missing. Subjects employed in the iron, steel, and metal industry formed the largest single group in the case series, then brick manufacturing and cement industry, transportation, and chemical industry (table 2). There was a slightly higher proportion of missing data on the branch of industry in control series $(29.0 \%)$ than in the case series $(26.3 \%)$. The broad group of various industrial or commercial branches with a mixed or unspecified exposure pattern formed the largest group. We report these numbers without giving estimates of $R R$ because we think that the high number of missing responses make such analyses less reliable. Instead, we focus on exposure to certain substances as given later. The data collected from next of kin confirmed the exposure to mineral dusts in
$24 \%$ of cases and $14 \cdot 1 \%$ of controls. The corresponding values for cement dust were $19 \%$ and $12.4 \%$, for metal dusts and metal fumes $23.7 \%$ and $15.3 \%$ (table 3).

Table 4 gives estimates of $R R$ for various substances (mineral dust, cement dust, metal dust) by histological type and by duration of exposure. All estimates were adjusted for smoking and age. In the left column only one substance is included in one model, whereas in the right column all substances are included simultaneously. In the univariate analysis all three substances showed increased risks for the group exposed longest. In the model where all substances were included simultaneously, estimated RRs were decreased due to positive correlation between these variables. The main conclusions should be drawn from the second model because this was adjusted for confounding. There remained a significant effect for mineral dust and metal dust in squamous cell carcinoma and for metal dust in small cell carcinoma. The effect of cement dust almost disappeared if adjusted for mineral dust and metal

Table 4 Estimates of RR and 95\% CIs for various exposures by histological subgroup for all cases

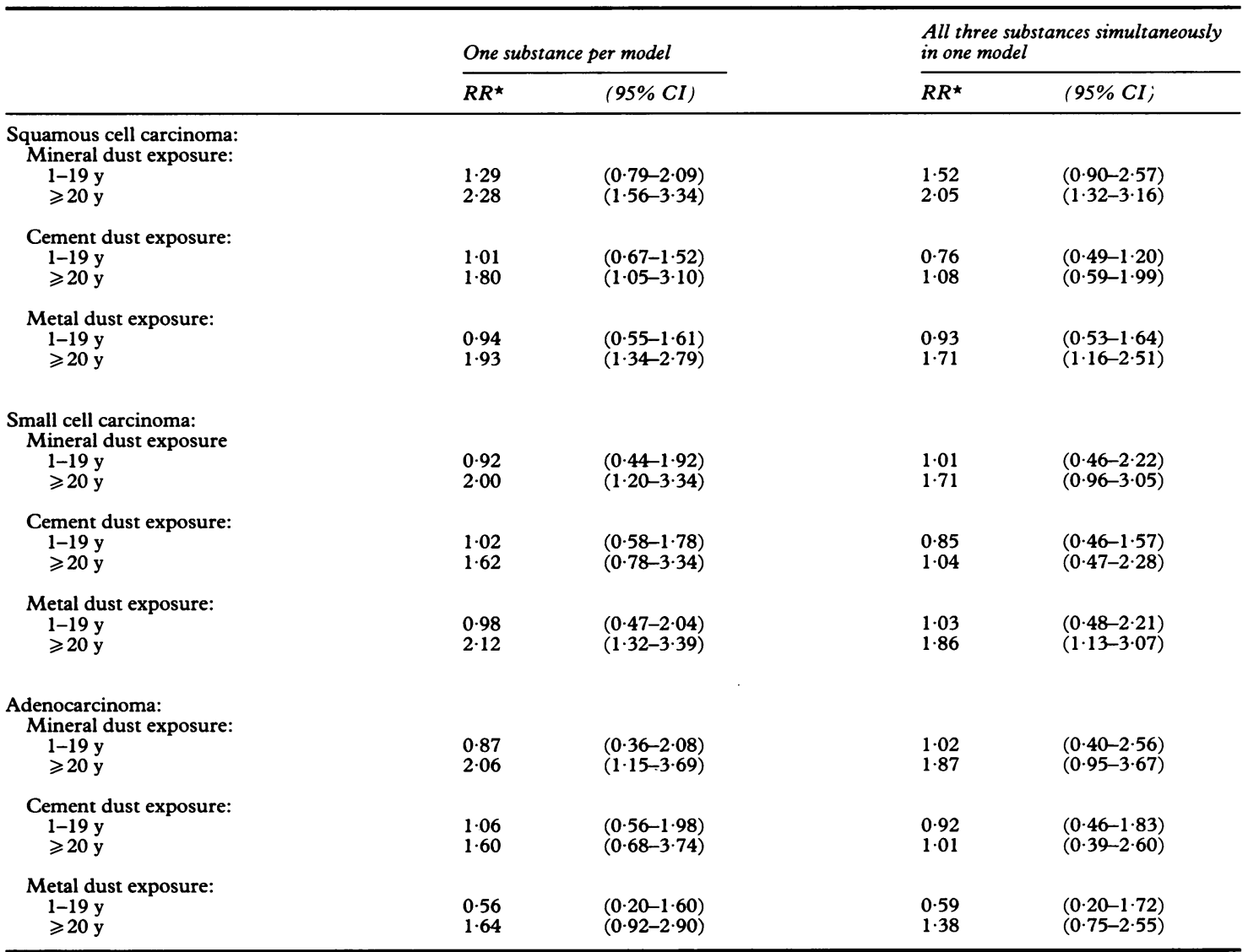

*Adjusted for smoking and age. 
Table 5 Estimates of RR and 95\% CI for various exposures by histological subgroup for cases under age 70

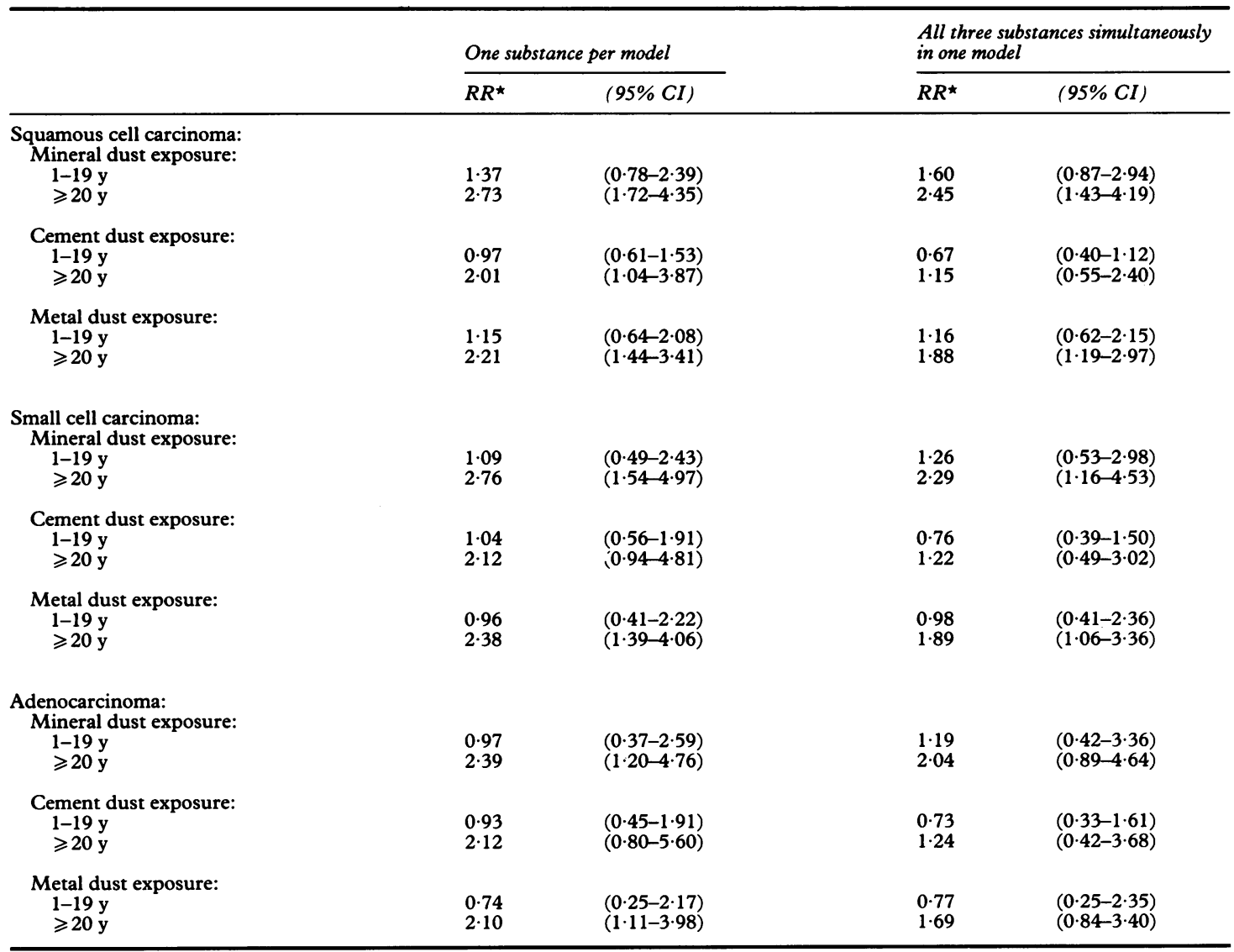

^Adjusted for smoking and age.

dust. We therefore conclude that the increased risk for exposure to cement dust in the first model is mostly due to confounding by the other occupational risk factors. The order of magnitude of the RRs (about 2) in the group exposed longest was similar for all histological types.

Table 5 shows results for the same models as in table 4, but for the subgroup of cases under 70 years of age. In comparison with the previous results estimates of RR were consistently increased by about $20 \%$ for long term exposure. A reduction of the risk after exposure had stopped is a possible explanation for this finding. Due to the high prevalence of occupational exposures in the population in Cracow, the calculated attributable risks were also high. We found values of $15.4 \%, 14.0 \%$, and $10.5 \%$ of cases attributable to the two most relevant exposures mineral dust and metal dust, for small cell carcinoma: squamous cell, and adenocarcinoma respectively. (For ages under 70 the corresponding numbers were $18.9 \%, 17.9 \%$, and $13.9 \%$.) These estimates are in accordance with the values found by Simonato et al. ${ }^{19}$

\section{Discussion}

The main purpose of this study was to determine whether lung cancer cell types are determined by types of environmental insults commonly encountered in industrial settings.

Interestingly, in assessing the magnitude of risk for lung cancer attributable to three broad industrial exposure categories (mineral dust, cement, metal dust and metal fumes) irrespective of the industrial branch, the health risk attributed to occupational dusts found additional confirmation. The findings showed that after controlling for age and smoking, all exposure categories, except for cement, affected the risk of lung cancer if the duration of exposure was longer than 20 years. It was shown that both exposure to mineral dusts of various origin and exposure to metal dusts and metal fumes were associated with higher risk for all lung cancer cell types. Estimates of RR for the two types of exposure (more than 20 years) were in the range 1.71 to 2.45 , the only exception being risk from metal dust exposure for adenocarcinoma, all ages with a value of 
1.38. This could be explained by statistical variation.

The similarity of all estimates of RR also justified a combined analysis (all cases $v$ controls). In such an analysis, estimates for exposure to mineral dust and metal dust (more than 20 years) had much lower statistical variation, which resulted in highly significant estimates.

Our results support the findings of some other studies: in a large case-referent study on association between several sites of cancer and exposure to exhaust and combustion of different substances the authors confirmed higher risk of lung cancer regarding squamous cell cancer among those workers who were exposed to diesel exhaust and employed in mining and quarrying, with an estimated adjusted RR of $2 \cdot 8$ (95\% CI 1.4-5.8). A subgroup of workers exposed to propane exhaust by handling materials showed an increased risk for squamous cell carcinoma $(R R=2 \cdot 3,95 \%$ CI $1 \cdot 0-5 \cdot 3)$. Exposure to coal combustion showed a significant RR for nonadenocarcinoma $(R R=1 \cdot 6,95 \%$ CI $1 \cdot 1-2 \cdot 3)$. Some of these findings were based on subgroups or small numbers; however, the main occupations for which exposure to the substance was coded were those for which an exposure to the dusts considered in this paper is also possible. ${ }^{22}$ Another study with related results is a large hospital based case-control study of cases of lung cancer performed in western Europe by Lubin and Blot. ${ }^{23}$ Despite the fact that our sample was smaller and interviews were taken from next of kin, there was a similar overall distribution of different histological types of lung cancer among men and an almost identical gradient of risk with cigarette smoking for both Kreyberg I carcinomas and adenocarcinoma. The authors found that any occupational exposure defined by job titles of five previous jobs was associated with increased risk for Kreberg I carcinomas, but not for adenocarcinoma. Duration and type of exposure to occupational air pollution were not considered.

Previous reports are equivocal for adenocarcinoma. Some early studies showed no or only slight association between occupation and adenocarcinoma. ${ }^{15}$ Other studies strongly suggested that occupation also increases risk of adenocarcinoma. For instance, Vena et $a l^{24}$ reported increased risk for adenocarcinoma in light smokers for employment in occupations with potential exposure to lung carcinogens. Specific job titles with probable moderate or heavy exposure to lung carcinogens were used for grouping. The authors found that the estimates of RR for adenocarcinoma among those who were nonsmokers and light smokers (0-39 pack-years) and were exposed to asbestos and aromatic hydrocarbons for more than 20 years were 3.0 and 6.7 respectively. Surprisingly, in heavy smokers (40 or more packyears) the estimates were not significant $(0.40$ and 0.93 respectively).
Some methodological problems should be considered in our study. Firstly, a substantial proportion of missing data on occupation has been found. Missed information concerned nearly the same proportion of cases and controls, however, and a selection bias would not be expected. It cannot be completely ruled out that relatives of cases may have a different attitude than relatives of controls in such a way that the former are more likely to link the occupation to the cause of death and therefore overreport exposures. On the other hand, this argument also holds for the controls as they have also died from some cause that the relatives may link to their occupation. The accompanying letter that was sent together with the questionnaire did not mention any specific hazards or previous hypothesis and rates of response were similar. Secondly, occupation and smoking habit as well as demographic variables were obtained from next of kin through mailed questionnaires. No data were available on the lifetime occupational history of the study participants and proxy respondents may not be able to provide accurate information about the occupational exposure of the study subjects. However, Lerchen and Samet ${ }^{25}$ assessing the validity of surviving wives as a source of information on occupational exposures of their husbands found that agreement for the usual job (the job held for the longest time) was $84 \%$ for industries and $\mathbf{7 8 \%}$ for occupations. There was about $100 \%$ agreement for cigarette smoking (ever, never). Thirdly, a histological diagnosis was only available for $43.8 \%$ of all cases with diagnosis of lung cancer on the death certificate. Therefore, cases represent a selection of the original database. The sample of cases with histological confirmation was comparable, however, with the total case series for potential confounders such as education or job category. Quality of information collected through mailed questionnaires could not be supported with independent information on occupational exposure from industrial records.

The analyses shown in tables 4 and 5 were also repeated deleting all subjects with missing response on branch of industry (complete case analysis). Estimates of RR for models shown in tables 4 and 5 changed little. This is further indication that a possible non-response bias is of low order of magnitude.

There are also other limitations that may have impact on the conclusions reached from this study. Some studies have indicated that both intraobserver and interobserver variation pose a problem in the classification of lung cancer. ${ }^{2627}$ The histological data in the study were obtained from clinical records and reflect judgments of a number of pathologists in the area; however, all of them were trained in the same pathology department of the Cracow Medical School. 
1 Wegman DH, Peters JM. Oat cell lung cancer in selected occupations. J Occup Med 1987;20:793-6.

2 Whitewell F, Newhouse ML, Bennett DR. A study of the histological cell types of lung cancer in workers suffering from asbestosis in the United Kingdom. Br J Ind Med 1974;31: 298-303.

3 Morton WE, Treyre EL. Histologic difference in occupational risks of lung cancer incidence. Am J Ind Med 1982;3:441-57.

4 Damber L, Larsson LG. Underground mining, smoking and lung cancer: a case-control study in the iron ore municipalities in northern Sweden. J Natl Cancer Inst 1985;74:1207-13.

5 Coggon D, Pannett B, Osmond C, Acheson ED. A survey of cancer and occupation in young and middle aged men. I Cancers of the respiratory tract. Br J Ind Med 1986;43:332-8.

6 Damber LA, Larsson LG. Occupation and male lung cancer: a case-control study in northern Sweden. Br J Ind Med 1987; 44:446-53.

7 Jöckel KH, Ahrens W, Wichmann HE, et al. Occupational and environmental hazards associated with lung cancer. Int $J$ Epidemiol 1992;21:202-13.

8 Delikoff IJ, Hammong EC, Churg J. Asbestos exposure, smoking and neoplasia. JAMA 1968;204:104-10.

9 Damber L, Larsson LG. Combined effects of mining and smoking in the causation of lung carcinoma. Acta Radiol Oncol 1982;21:305-13.

10 Wittemore AS, McMilhan A. Lung cançer mortality among US uranium miners: a reappraisal. J Natl Cancer Inst 1983;71: 489-99.

11 Pershagen G, Wall S, Taube A, Linman L. On the interaction between occupational arsenic exposure and smoking and its relationship to lung cancer. Scand J Work Environ Health 1981;7:302-9.

12 Jedrychowski W, Becher $\mathrm{H}$, Wahrendorf J, Basa-Cierpialek Z. Case-control study of lung cancer with special reference to the effect of air pollution in Poland. $J$ Epidemiol Community Health 1990;44:114-20.

13 Vena JE. Air pollution as a risk factor in lung cancer. $\mathrm{Am} \mathrm{J}$ Epidemiol 1982;116:42-56.

14 Doll R, Hill AB, Kreyberg L. The significance of cell type in relation to the aetiology of lung cancer. $B r J$ Cancer 1957; 11:43-8.

15 Kreyberg L. Histological lung cancer types. A morphological and biological correlation. Acta Pathologica et Microbiologica Scandinavia 1962;157(suppl):1-64.

16 Stayner LT, Wegmann DH. Smoking, occupation, and histopathology of lung cancer: A case-control study with the use of the Third National Cancer Survey. J Natl Cancer Inst 1983; 70:421-5.

17 Wynder EL, Corey LS. Epidemiologic patterns in lung cancer by histologic type. Eur J Cancer 1987;23:1491-6.

18 Hoar Zahm S, Brownson RC, Chang JC, Davis JR. Study of lung cancer histologic types, occupation, and smoking in Missouri. Am J Ind Med 1989;15:565-78.

19 Simonato L, Vineis P, Fletcher AC. Estimates of the proportion of lung cancer attributable to occupational exposure. Carcinogenesis 1988;9:1159-65.

20 Jedrychowski W, Becher H, Wahrendorf J, Basa-Cierpialek Z, Gomola K. Effect of tobacco smoking on various histologic types of lung cancer. Journal of Cancer Research and Clinical Oncology 1992;118:276-82.

21 Breslow NE, Day NE. Statistical methods in cancer research. Vol 1. The analysis of case-control studies. Lyon: International Agency for Research on Cancer, 1980. (IARC sci publ No 32.)

22 Siemiatycki J, Gerin M, Stewart P, Nordon L, Dewar R Richardson L. Associations between several sites of cancer and ten types of exhaust and combustion products. Results from a case-referent study in Montreal. Scand J Work Environ Health 1988;14:79-90.

23 Lubin JH, Blot WJ. Assessment of lung cancer risk factors by histologic category. J Natl Cancer Inst 1984;73:383-9.

24 Vena JW, Byers TE, Cookfair D, Swanson M. Occupation and lung cancer risk. An analysis by histologic subtypes. Cancer 1985;56:910-7.

25 Lerchen ML, Samet JM. An assessment of the validity of questionnaire response provided by a surviving spouse. $\mathrm{Am} \mathrm{J}$ Epidemiol 1986;123:481-9.

26 Feinstein AR, Gelfman NA, Yesner R, Auerbach O, Hackel DB, Pratt PC. Observer variability in the histopathologic diagnosis of lung cancer. Am Rev Respir Dis 1970;100:671-84.

27 Carr DT. Histopathology of lung cancer. Int J Epidemiol 1990;19 (suppl 1):8-10.

Accepted 1 June 1992

\section{Correspondence and editorials}

The British Journal of Industrial Medicine welcomes correspondence relating to any of the material appearing in the journal. Results from preliminary or small scale studies may also be published in the correspondence column if this seems appropriate. Letters should be not more than $\mathbf{5 0 0}$ words in length and contain a minimum of references. Table and figures should be kept to an absolute minimum. Letters are accepted on the understanding that they may be subject to editorial revision and shortening.

The journal now also publishes editorials which are normally specially commissioned. The Editor welcomes suggestions regarding suitable topics; those wishing to submit an editorial, however, should do so only after discussion with the Editor. 